\title{
Phylogenic analysis of human bocavirus detected in children with acute respiratory infection in Yaounde, Cameroon
}

\author{
Sebastien Kenmoe ${ }^{1,2,3}$, Marie-Astrid Vernet ${ }^{1}$, Mohamadou Njankouo-Ripa', Véronique Beng Penlap², \\ Astrid Vabret ${ }^{3}$ and Richard Njouom ${ }^{1 *}$ (1)
}

\begin{abstract}
Objective: Human Bocavirus (HBoV) was first identified in 2005 and has been shown to be a common cause of respiratory infections and gastroenteritis in children. In a recent study, we found that $10.7 \%$ of children with acute respiratory infections (ARI) were infected by HBoV. Genetic characterization of this virus remains unknown in Central Africa, particularly in Cameroon Leeding us to evaluate the molecular characteristics of HBoV strains in Cameroonian children with ARI.

Results: Phylogenetic analysis of partial HBoVVP1/2 sequences showed a low level of nucleotide variation and the circulation of HBoV genotype 1 (HBoV-1) only. Three clades were obtained, two clustering with each of the reference strains ST1 and ST2, and a third group consisting of only Cameroon strains. By comparing with the Swedish reference sequences, ST1 and ST2, Cameroon sequences showed nucleotide and amino acid similarities of respectively 97.36-100\% and $98.35-100 \%$. These results could help improve strategies for monitoring and control of respiratory infections in Cameroon.
\end{abstract}

Keywords: Human bocavirus, Children, Acute respiratory infection, Cameroon, Africa

\section{Introduction}

During the past two decades, new molecular techniques have contributed to the discovery of many viruses. This was the case in September 2005 with the discovery of the Human Bocavirus (HBoV) by a Swedish research team [1]. HBoV was subsequently named $\mathrm{HBoV}-1$. Since, three other species (HBoV-2, 3, and 4) have been described from stool samples in Pakistan, Australia, and Nigeria respectively [2-4]. Based on phylogenetic analysis of $\mathrm{HBoV}$ genomic sequences, it was assigned to the Parvoviridae family, Parvovirinae sub-family, and Bocavirus genus. Indeed, the sequences identified were closely related to two other bocaviruses: the Bovine Parvovirus and the canine Minute Virus. Although this classification was based on genetic characterization, microscopy

\footnotetext{
*Correspondence: njouom@pasteur-yaounde.org

${ }^{1}$ Virology Unit, Centre Pasteur of Cameroon, Yaounde, BP 1274 Yaounde, Cameroon

Full list of author information is available at the end of the article
}

studies have observed viral particles having the characteristics of this family of viruses; small DNA viruses with unenveloped icosahedral capsid and a diameter ranging from 18 to $26 \mathrm{~nm}$. The $\mathrm{HBoV}$ genome is a $5.2 \mathrm{~kb}$ linear negative sense single-stranded DNA. During the 8th ICTV report it was decided that the different species of the genus Bocavirus should show a similarity in the NS1 gene of at least $95 \%$. Based on the analysis of a large number of VP1 gene sequences and calculations of the genetic distance of complete genomes of different species of $\mathrm{HBoV}$, Kapoor and collaborators recently proposed a new classification mode for $\mathrm{HBoV}$ suggesting that $\mathrm{HBoV}$ strains with more than 8 and $10 \%$ difference respectively in protein and nucleotide sequences of the VP1 complete gene should be considered as different species. Those with more than respectively 1.5 and $5 \%$ difference should be considered as different genotypes [3]. This proposal is consistent with the current nomenclature of the four $\mathrm{HBoV}$ species. A decade 
after the identification of $\mathrm{HBoV}-1$ in Sweden, it has been detected at frequencies ranging from 2 to $19 \%$ [5] in several countries across Europe [6-9], Asia [10-13], America [14-17], Africa [18-21], Middle East [22-24], and Australia [4, 25], revealing an overall distribution of this virus. These studies indicate that $\mathrm{HBoV}-1$ is primarily a respiratory pathogen. $\mathrm{HBoVs}$ are detected not only in the respiratory tract ( $\mathrm{HBoV}-1$ and 2$)$, but also in the gastrointestinal tract $(\mathrm{HBoV}-1$ to 4$)$ where they are associated with gastroenteritis [5]. HBoV are highly conserved viruses and sequences obtained in various regions of the world by several groups highlight a high homology of genetic sequences $[7,9,11,18,22]$.

In a recent study, we have found that $10.7 \%$ of children with acute respiratory infections (ARI) were infected by a HBoV [21]. However, most molecular epidemiology studies of HBoVs have been performed in developed countries [5]. Genetic characterization of this virus remains unknown in most African countries, particularly in Cameroon. This study is, to our knowledge, the first analysis of the genetic characteristics of HBoVs obtained from Cameroonian children with acute respiratory infections (ARI).

\section{Methods}

\section{Study population and samples}

The study population was hospitalized and outpatient children with ARI consulting at the pediatric service of 'Centre Hospitalier d'Essos' in Yaounde, Cameroon. Demographic and clinical characteristics of these children have been previously described [21]. For this study nasopharyngeal swab samples were used.

\section{Laboratory analysis}

DNA was extracted using QIAamp DNA Mini kit (Qiagen, Hiden, Germany, Cat No. 51306) from nasopharyngeal swab specimens following the manufacturer's instructions. A final elution volume of $200 \mu \mathrm{L}$ of DNA was stored $\mathrm{a}-80{ }^{\circ} \mathrm{C}$ prior to testing by a commercially available duplex real time PCR for the detection of human Adenovirus and $\mathrm{HBoV}$ (Respiratory Multi Well System r-gene $^{\mathrm{TM}}$, BioMerieux, Lyon, France, Cat No. 1092480) following the manufacturer's instructions. $\mathrm{HBoV}$ positive samples were then selected and a fragment of the VP1/2 capsid gene was amplified by semi-nested PCR as described elsewhere [18]. Briefly, $10 \mu \mathrm{L}$ of the DNA was added to $50 \mu \mathrm{L}$ of PCR mixture containing of $24.5 \mu \mathrm{L}$ of water, $1.5 \mu \mathrm{L}$ of $\mathrm{MgCl}_{2}$ at $50 \mathrm{mM}, 1 \mu \mathrm{L}$ dNTPs at $10 \mathrm{mM}$, $2,5 \mu \mathrm{L}$ of VP-A sense primer (5'-GCACTTCTGTATCAGATGCCTT-3') at $10 \mu \mathrm{M}, 2.5 \mu \mathrm{L}$ of VP-B reverse primer (5'-CGTGGTATGTAGGCGTGTAG-3') at $10 \mu \mathrm{M}, 5 \mu \mathrm{L}$ of $10 \times$ PCR buffer, $2.5 \mu \mathrm{L}$ of the W1 solution at $1 \%$, and $0.5 \mu \mathrm{L}$ of the Taq DNA Polymerase (Invitrogen, USA, Cat No. 10342053). To improve the sensitivity, a second semi-nested reaction with $2 \mu \mathrm{L}$ of the first PCR product was performed with the pair of primer VB-B and VP-C (5'-CTTAGAACTGGTGAGAGCACTG-3') according to the previous protocol. The cycling parameters for the two PCR included an enzyme activation and initial denaturation at $94{ }^{\circ} \mathrm{C}(3 \mathrm{~min}) ; 40$ cycles of denaturation at $94{ }^{\circ} \mathrm{C}$ (45 s), primer annealing at $50{ }^{\circ} \mathrm{C}(30 \mathrm{~s})$ and extension at $72{ }^{\circ} \mathrm{C}(1 \mathrm{~min} 30 \mathrm{~s})$; a final extension at $72{ }^{\circ} \mathrm{C}(10 \mathrm{~min})$, and a hold at $4{ }^{\circ} \mathrm{C}$. The amplified VP1/2 capsid of $980 \mathrm{bp}$ product was observed after electrophoresis in a $1.5 \%$ agarose gel.

The VP1/2 capsid PCR products were purified and sequenced using Big Dye Terminator cycle sequencing (Applied Biosystems, Foster City, USA, Cat No. $4,337,454)$ and semi-nested PCR primers according manufacturer instructions. Electrophoresis and data collection were done on an Applied Biosystems AB3100 genetic analyzer. Sequences were first aligned and edited using Sequence Navigator1 software (Applied Biosystems, Foster City, CA). The consensus sequence was generated by removing low quality base peaks at the end of the chromatogram and correcting base pair mismatches.

\section{Phylogenetic analysis}

Genotypes were determined by phylogenetic analysis comparing the consensus sequence of each sample to reference VP1/2 capsid sequences including the Swedish reference sequences ST1 and ST2, and reference sequences of HBoV-2 (NC_012042), HBoV-3 (NC_012564), HBoV-4 (NC_012729), BPV (NC_001540.1), and MVC (NC_004442.1).

Phylogenetic analyses were performed using MEGA software version 6 [26]. Briefly, sequences in FASTA format were aligned using Clustal W algorithm. Genetic distances were measured with the Kimura-2 parameter model. A phylogenetic tree was constructed with the neighbor-joining algorithm and robustness of the tree was evaluated with 1000 bootstrap resamplings.

The MEGA software version 6 was used to generate predicted amino acid sequences from consensus nucleotide sequences by translation. The comparison of the sites and proportion of similarities at amino acid and nucleotide levels was made between consensus amino acid and nucleotide sequences of each Cameroonian $\mathrm{HBoV}$ sequences and ST1 and ST2 reference sequences.

All consensus nucleotide sequences obtained in this study were submitted to GenBank Database under accession numbers KX121135 to KX121163.

\section{Results}

Genotyping of HBoV isolates

Among the $80 \mathrm{HBoV}$ positive samples, DNA in the VP1/2 capsid region could be amplified, sequenced and analysed 


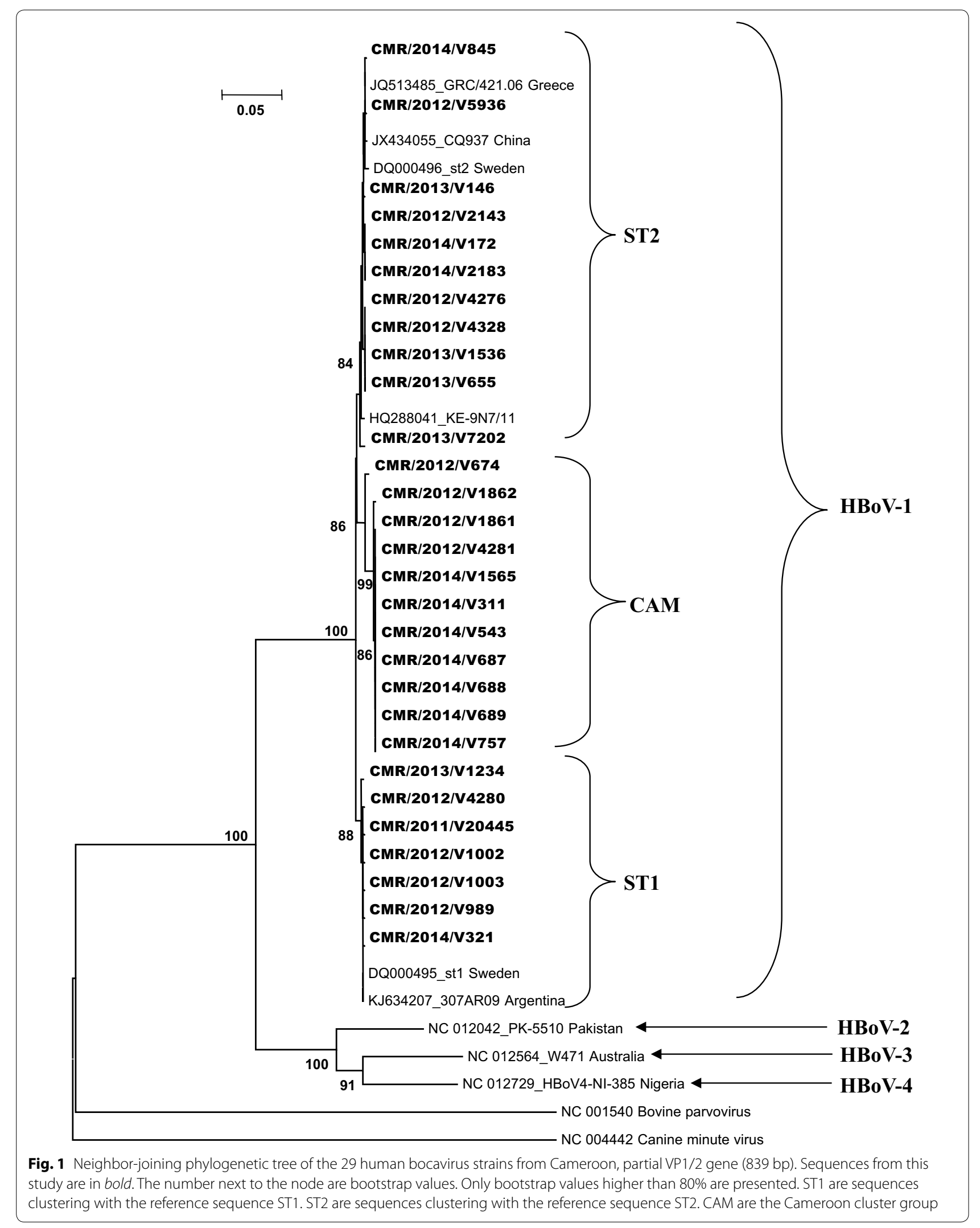


phylogenetically in 29 samples (36.2\%). The estimated phylogeny of these sequences and previously published VP1/2 capsid sequences including those of the four species of $\mathrm{HBoV}$ is shown in Fig. 1. All of the 29 sequences clustered with $\mathrm{HBoV}-1$ reference sequences. Three clades were obtained, two clustering with each of the reference strains ST1 and ST2, and a third group consisting of only Cameroon strains (CAM).

By comparing with the Swedish reference sequences ST1 and ST2, Cameroon sequences showed nucleotide and amino acid similarities of respectively $97.36-100 \%$ and $98.35-100 \%$.

\section{Nucleotide and aminoacid polymorphisms}

Based on the VP1/2 capsid gene of the Swedish reference strain (accession number NC_007455), 28 of 717 nucleotides analyzed (position 1141-1857 of VP1/2 capsid gene) were found to be variable, with 21 (75\%) transitions and 7 (25\%) transversions. Ten nucleotide substitutions (G1243A, C1429T, G1470A, A1539G, C1542T, A1551G, T1619A, A1636C, T1800C, and A1821G) were specific to the Cameroonian clade: CAM (data not shown and available upon request). The description of the amino acid sequences deduced from $\mathrm{HBoV}-1$ strains of this study was made with reference to the VP1/2 capsid domain of HBoV reference (accession number NC_007455), which extended over a length of 239 amino acids (position 381619). The HBoV strains analyzed in the study had the amino acid substitutions: G415S, N474S, F540Y, N546H, and $5590 \mathrm{~T}$ (data not shown and available upon request). Three of these amino-acid substitutions (G415S, F540Y, and $\mathrm{N} 546 \mathrm{H}$ ) were specific to the CAM clade.

\section{Discussion}

This study reports for the first time molecular characteristics of $\mathrm{HBoV}$ in children suffering from acute respiratory infections in Cameroon. Only 29 (36.2\%) tested samples were amplified by genotyping PCR on the VP1/2 capsid gene during this study. This low amplification rate can be explained by the high sensitivity of the detection technique compared to the genotyping technique, and also by the low viral load in unamplified samples (mean cycle threshold unamplified samples $=35.6 \pm 1.8$ vs. $28.1 \pm 6.3$ for the positive, $\mathrm{p}<0.001)$. Several studies have shown that HBoV-1 is a respiratory pathogen [5]. As expected, phylogenetic analysis of partial VP1/2 capsid gene sequences obtained in this study also revealed the presence of the $\mathrm{HBoV}-1$ species. These viruses circulating among children with acute respiratory infections in Cameroon were divided into two genetic clades closely linked to ST1 and ST2 and a third clade made only of Cameroonian strains. The sequences revealed an extremely high homology with the original sequences (ST1 and ST2) identified in Sweden in 2005. These results are consistent with findings of other authors from around the world [6, $7,23]$. However, unlike these results and others $[6,7,15-$ $17,23]$, over 10 nucleotide substitutions leading to three amino acid mutations were specific to the CAM clade, suggesting that $\mathrm{HBoV}$ undergo higher selective pressures in Yaounde, Cameroon than in other regions.

Our study included limited number of patients from a single health care facility and is therefore not representative of our country. However, our sequences are also similar to those circulating in other countries, highlighting the low genetic variability of $\mathrm{HBoV}$. In summary, our data indicates that $\mathrm{HBoV}-1$ strains collected from 2011 to 2014 in Yaounde are divided in three groups. Two groups clustered with previously reported ST1 and ST2 genotypes, and the third group is an original Cameroonian genotype. The partial HBoV-1 VP1/2 gene sequences in Cameroon have relatively high genetic variations compared to others studies.

\section{Limitations}

Our study included limited number of patients from a single health care facility and is therefore not representative of our country.

\section{Authors' contributions \\ RN, AV and VBP designed the study. SK, M-AV and MN-R carried out and inter- preted experiments. SK conducted phylogenetic analyses and wrote the first draft of the paper. All authors read and approved the final manuscript. \\ Author details \\ ${ }^{1}$ Virology Unit, Centre Pasteur of Cameroon, Yaounde, BP 1274 Yaounde, Cameroon. ${ }^{2}$ Biochemistry Department, Université of Yaounde 1, Yaounde, Cameroon. ${ }^{3}$ Virology Service, Pôle de Biologie, CHU de Caen, Caen, France.}

\section{Acknowledgements}

We thank all laboratory and hospital staff involved data and respiratory samples collection used for this study and Dr. Matthieu Schoenhals for his assistance with the English language.

\section{Competing interests}

The authors declare that they have no competing interests.

\section{Availability of data and materials}

All HBoV sequences analyzed in this study where published on Genbank with accession number KX121135 to KX121163.

\section{Ethics approval and consent to participate}

Written informed consent was obtained from parents or guardians of all children enrolled in the study. The procedures of the original study (IMMI project) have been evaluated and approved by the National Research Ethics Committee and the Ministry of Health of Cameroon.

\section{Funding}

This work was supported by the U.S. Department of Health and Human Services (DHHS) Grant Number 6 DESP060001-01-01 via the International Network of Pasteur Institutes and the Institut de Microbiologie et de Maladies Infectieuses' (IMMI) in France.

\section{Publisher's Note}

Springer Nature remains neutral with regard to jurisdictional claims in published maps and institutional affiliations. 
Received: 12 April 2017 Accepted: 12 July 2017

Published online: 17 July 2017

\section{References}

1. Allander T, Tammi MT, Eriksson M, Bjerkner A, Tiveljung-Lindell A, Andersson $B$. Cloning of a human parvovirus by molecular screening of respiratory tract samples. Proc Natl Acad Sci USA. 2005;102:12891-6.

2. Kapoor A, Slikas E, Simmonds P, Chieochansin T, Naeem A, Shaukat S, et al. A newly identified bocavirus species in human stool. J Infect Dis. 2009;199:196-200.

3. Kapoor A, Simmonds P, Slikas E, Li L, Bodhidatta L, Sethabutr O, et al. Human bocaviruses are highly diverse, dispersed, recombination prone, and prevalent in enteric infections. J Infect Dis. 2010;201:1633-43.

4. Arthur JL, Higgins GD, Davidson GP, Givney RC, Ratcliff RM. A novel bocavirus associated with acute gastroenteritis in Australian children. PLoS Pathog. 2009;5:e1000391.

5. Jartti T, Hedman K, Jartti L, Ruuskanen O, Allander T, Söderlund-Venermo M. Human bocavirus_the first 5 years. Rev Med Virol. 2012;22:46-64.

6. Pogka V, Moutousi A, Kossyvakis A, Kalliaropoulos A, Sgouras DN, Giannaki $M$, et al. Genetic variability of human metapneumo-and bocaviruses in children with respiratory tract infections. Influenza Other Respir Viruses. 2014:8:107-15.

7. Zappa A, Canuti M, Frati E, Pariani E, Perin S, Ruzza ML, et al. Co-circulation of genetically distinct human metapneumovirus and human bocavirus strains in young children with respiratory tract infections in Italy. J Med Virol. 2011;83:156-64

8. Guido M, Quattrocchi M, Campa A, Zizza A, Grima P, Romano A, et al. Human metapneumovirus and human bocavirus associated with respiratory infection in Apulian population. Virology. 2011:417:64-70.

9. Dina J, Vabret A, Gouarin S, Petitjean J, Lecoq J, Brouard J, et al. Detection of human bocavirus in hospitalised children. J Paediatr Child Health. 2009;45:149-53.

10. Lu Q-B, Wo Y, Wang H-Y, Huang D-D, Zhao J, Zhang X-A, et al. Epidemic and molecular evolution of human bocavirus in hospitalized children with acute respiratory tract infection. Eur J Clin Microbiol Infect Dis. 2015;34:75-81.

11. Alam MM, Khurshid A, Shaukat S, Sharif S, Suleman RM, Angez M, et al. Human bocavirus in Pakistani children with gastroenteritis. J Med Virol. 2015:87:656-63.

12. Tran DN, Nguyen TQN, Nguyen TA, Hayakawa S, Mizuguchi M, Ushijima H. Human bocavirus in children with acute respiratory infections in Vietnam. J Med Virol. 2014:86:988-94.
13. Ahn JG, Choi SY, Kim DS, Kim KH. Human bocavirus isolated from children with acute respiratory tract infections in Korea, 2010-2011. J Med Virol. 2014:86:2011-8.

14. Ghietto LM, Cámara A, Zhou Y, Pedranti M, Ferreyra S, Frey T, et al. High prevalence of human bocavirus 1 in infants with lower acute respiratory tract disease in Argentina, 2007-2009. Braz J Infect Dis. 2012;16:38-44.

15. Longtin J, Bastien M, Gilca R, Leblanc E, de Serres G, Bergeron MG, et al. Human bocavirus infections in hospitalized children and adults. Emerg Infect Dis. 2008;14:217-21.

16. Bastien N, Chui N, Robinson JL, Lee BE, Dust K, Hart L, et al. Detection of human bocavirus in Canadian children in a 1-year study. J Clin Microbiol. 2007:45:610-3

17. Kesebir D, Vazquez M, Weibel C, Shapiro ED, Ferguson D, Landry ML, et al. Human bocavirus infection in young children in the United States: molecular epidemiological profile and clinical characteristics of a newly emerging respiratory virus. J Infect Dis. 2006;194:1276-82.

18. Misigo D, Mwaengo D, Mburu D. Molecular detection and phylogenetic analysis of Kenyan human bocavirus isolates. J Infect Dev Ctries. 2014;8:221-7

19. Smuts H, Workman L, Zar HJ. Role of human metapneumovirus, human coronavirus NL63 and human bocavirus in infants and young children with acute wheezing. J Med Virol. 2008:80:906-12.

20. Smuts $H$, Hardie D. Human bocavirus in hospitalized children. S Afr Emerg Infect Dis. 2006;12:1457-8.

21. Kenmoe S, Tchendjou P, Vernet M-A, Moyo-Tetang S, Mossus T, NjankouoRipa M, et al. Viral etiology of severe acute respiratory infections in hospitalized children in Cameroon, 2011-2013. Influenza Other Respir Viruses. 2016;10(5):386-93.

22. Abdel-Moneim AS, Kamel MM, Al-Ghamdi AS, Al-Malky MIR. Detection of bocavirus in children suffering from acute respiratory tract infections in Saudi Arabia. PLoS ONE. 2013:8:e55500.

23. Nadji SA, Poos-Ashkan L, Khalilzadeh S, Baghaie N, Shiraghaei MJ, Hassanzad $M$, et al. Phylogenetic analysis of human bocavirus isolated from children with acute respiratory illnesses and gastroenteritis in Iran. Scand J Infect Dis. 2010;42:598-603.

24. Hindiyeh MY, Keller N, Mandelboim M, Ram D, Rubinov J, Regev L, et al. High rate of human bocavirus and adenovirus coinfection in hospitalized Israeli children. J Clin Microbiol. 2008:46:334-7.

25. Sloots TP, McErlean P, Speicher DJ, Arden KE, Nissen MD, Mackay IM. Evidence of human coronavirus HKU1 and human bocavirus in Australian children. J Clin Virol. 2006;35:99-102.

26. Tamura K, Stecher G, Peterson D, Filipski A, Kumar S. MEGA6: molecular evolutionary genetics analysis version 6.0. Mol Biol Evol. 2013;30:2725-9.

\section{Submit your next manuscript to BioMed Central and we will help you at every step:}

- We accept pre-submission inquiries

- Our selector tool helps you to find the most relevant journal

- We provide round the clock customer support

- Convenient online submission

- Thorough peer review

- Inclusion in PubMed and all major indexing services

- Maximum visibility for your research

Submit your manuscript at www.biomedcentral com/submit
BioMed Central 